\title{
RELAÇÓES ENTRE FAMÍLIAS E INSTITUIÇÓES DE EDUCAÇÃO INFANTIL: O COMPARTILHAMENTO DO CUIDADO E EDUCAÇÃO DAS CRIANÇAS ${ }^{1}$
}

\author{
RELATIONSHIPS BETWEEN FAMILIES AND INSTITUTIONS OF \\ EARly CHILDHOOd EduCATION: THE SHARING OF CARE AND \\ CHILDREN'S EDUCATION
}

\begin{abstract}
Isabel de Oliveira e Silva
Doutorado em Educaçáo pela Universidade Federal de Minas Gerais. Professora Associada do Departamento de Métodos e Técnicas de Ensino e do Programa de PósGraduação em Educação da Universidade Federal de Minas Gerais. Membro do Núcleo de Estudos e Pesquisas sobre Infância e Educaçấo Infantil - NEPEI/FaE/UFMG. Minas Gerais - MG - Brasil

ORCID: https://orcid.org/000o-0003-2223-4548 isabel.os@uol.com.br

Iza Rodrigues da Luz

Doutorado em Educação pela Universidade Federal de Minas Gerais. Professora Associada do Departamento de Ciências Aplicadas à Educação e do Programa de PósGraduação em Educação da Universidade Federal de Minas Gerais. Membro do Núcleo de Estudos e Pesquisas sobre Infância e Educação Infantil - NEPEI/FaE/UFMG. Minas Gerais - MG - Brasil ORCID: https://orcid.org/0000-0002-4772-I329 izarodriguesluz@gmail.com
\end{abstract}

Resumo: O objeto deste artigo é a relação entre famílias e a instituição de Educação Infantil (IEI) e buscou responder à seguinte pergunta: que significados os familiares constroem sobre a frequência de suas crianças à IEI? O enfoque adotado foi o da análise compreensiva do fenômeno das relaçóes entre famílias e escola, com o propósito de elucidar as possibilidades do compartilhamento do cuidado e educação de bebês e crianças de 0 a 5 anos como funçấo da Educação Infantil. A pesquisa, de caráter qualitativo, abrangeu diferentes instrumentos de construção de dados, dentre os quais a realização de grupos focais com familiares, que constituem as fontes empíricas analisadas neste artigo. A categoria central discutida é o compartilhamento e seus elementos constitutivos. Como resultados, a pesquisa revelou que o compartilhamento do cuidado e educaçáo das crianças apresenta dimensóes espaço-temporais que extrapolam os tempos e espaços da escola e se relaciona com processos de construção da confiança, segurança e bem-estar de crianças e adultos.

Palavras-chave: Compartilhamento; Educação Infantil; Famílias.

ABSTRACT: This article analyzes the relationship between families and the Institution of Early Childhood Education and has as a major concern the sharing of care and education duties of babies and children from o to 5 years old. We aim to answer the 
following question: what meanings do families construct about the frequency of their children to those institutions? We adopted the comprehensive analysis approach in order to understand the relationships between families and school aiming to clarify the possibilities of care and education sharing as a role of the Early Childhood Education. Our data come from focal groups with the families. The main category discussed is sharing and its constitutive elements. As results, the research revealed that the sharing of children's care and education has space-time dimensions which go beyond the school's times and spaces and is related to the process of building trust, safety and wellbeing among children and adults.

KeYwords: Sharing; Early Childhood Education; Families.

\section{O compartilhamento do cuidado e da educaçáo de bebês e crianças pequenas}

O reconhecimento de que a Educação Infantil é direito das crianças a um ambiente educativo que proporcione experiências que enriqueçam suas condiçốes de desenvolvimento é não apenas um consenso na área, mas, também, uma conquista no plano legal que ainda não foi plenamente implementada na realidade brasileira. Ao lado do direito das crianças está o reconhecimento de que a Educação Infantil é também direito das famílias trabalhadoras a contarem com apoio no cuidado e educação dos filhos. A Constituição Federal de 1988 é explícita nesse sentido, ao definir que creche e pré-escola são instituiçóes educacionais a que têm direito as crianças de o a 5 anos e as famílias trabalhadoras. (BRASIL, I988, art. 208)

Todos os instrumentos normativos decorrentes visam dar consequências práticas a esses direitos, especialmente a Lei n. 9.394, que fixou as Diretrizes e Bases da Educação (LDB) (BRASIL, I996), e a Resolução n. 5 do Conselho Nacional de Educação (CNE), que estabeleceu as Diretrizes Curriculares Nacionais para a Educação Infantil (DCNEI) (BRASIL, 2009). As DCNEI seguem as definiçóes legais e apresentam princípios, fundamentos e procedimentos para os sistemas de ensino e para as instituições de Educação Infantil. Entre as especificaçôes relativas às propostas pedagógicas das Instituições de Educação Infantil (IEI), determinam, no art. $7^{\circ}$, inciso II, que:

na observância destas Diretrizes, a proposta pedagógica das instituiçôes de Educação Infantil deve garantir que elas cum- 
pram plenamente sua função sociopolítica e pedagógica: [...] II - assumindo a responsabilidade de compartilhar e complementar a educação e cuidado das crianças com as famílias. (BRASIL, 2009)

Essa determinação expressa as construções que, ao longo das últimas 4 décadas, mobilizaram amplos setores da sociedade brasileira, incluindo movimentos sociais de luta pelos direitos das mulheres e das crianças, intelectuais e pesquisadores(as) do campo da educação, bem como instâncias do poder público. Essa construção tem início com a crítica aos modelos assistencialistas que deram origem às creches no país, voltadas ora para a assistência à criança desvalida, órfã e pobre, ora como forma de favorecer o ingresso das mulheres no mercado de trabalho (VIEIRA, I988; KHULMANN JR., I998; HADDAD, I99I; ROSEMBERG, I989; SILVA, 2008). As análises históricas demonstraram que o discurso que sustentou a defesa da criação de instituiçôes de atendimento às crianças nos seis primeiros anos de vida, a partir do início do século XX, no Brasil, indicavam um projeto assistencial e, não raro, assistencialista, com forte cunho higienista e preconceituoso em relação às famílias pobres da nossa sociedade (VIEIRA, I986; KHULMANN JR., I998). Nessa direção, as funções atribuídas a essas instituições eram as de substituição das famílias, particularmente das mães, no cuidado e educação das crianças pequenas, cumprindo, assim, o objetivo de compensar carências econômicas, sociais, culturais e até afetivas (VIEIRA, 1988). Sua trajetória ocorre paralelamente à do campo educacional, que apenas timidamente apresentou iniciativas de educação pré-escolar inseridas nos marcos propriamente educativos.

A ausência de identidade desse atendimento também foi e tem sido largamente discutida pelos especialistas da área (HADDAD, I99I), na medida em que a subdivisão entre creche e pré-escola só vem a ocorrer em 1996 com a incorporação, pela LDB, da faixa etária de o a 5 anos e, por consequência, da expressáo Educação Infantil. A literatura da área tem identificado conflitos e tensóes presentes no atendimento às necessidades dos diferentes atores envolvidos: crianças, pais ou responsáveis (familiares), professoras(es) e as instituições de Educação Infantil (IEI) (ROSEMBERG, 200I; RAPOPORT; PICCININI, 2004; MARANHÃO; SARTI, 2007; SILVA, 20I4; MONÇÃO, 20I5). Questôes decorrentes da recente entrada 
dos bebês e crianças entre o e 5 anos nos sistemas de ensino exigem a definição de responsabilidades por parte das IEI, que devem prover o cuidado e a educação ao mesmo tempo em que as famílias também o fazem, em um regime de complementaridade. Embora em alguma medida esse elemento esteja presente em toda a Educação Básica, uma vez que as crianças e jovens se encontram sob a responsabilidade das famílias com as quais a escola interage (NOGUEIRA, 2006), no caso da Educação Infantil, outros aspectos se interpóem. $\mathrm{O}$ mais visível deles se relaciona com as funçóes dessa etapa, relativas às necessidades que foram constituídas na nossa cultura como pertinentes ao ambiente doméstico, portanto, afetas à esfera privada: cuidados básicos de proteção à integridade, apoio para a alimentação, a higiene e demais condiçóes para a progressiva conquista da autonomia no autocuidado.

Neste artigo, focalizamos as questóes relativas à concomitância dos sujeitos e das açôes (de cuidado e educação) no ambiente privado e no ambiente educacional público. Mais especificamente, nos perguntamos que significados os familiares constroem sobre a frequência de suas crianças à IEI e como ocorrem as relaçôes entre esses dois atores responsáveis pelas crianças de o a 5 anos: familiares e profissionais das IEI.

A literatura revela que as relações entre as instituiçôes de Educação Infantil e as famílias são marcadas por tensôes que se apresentam com características distintas daquelas que ocorrem nos demais níveis da educação básica. Especialmente as açóes de cuidados com as crianças (mais intensas quanto mais novas elas são) e as alterações cotidianas que a frequência à IEI impooe às famílias (SILVA, 20I4) constituem elementos que desencadeiam e/ou explicam dificuldades nas relaçóes entre os atores adultos. Por outro lado, a frequência à Educação Infantil tem sido cada vez mais reconhecida como um valor para as famílias que demandam vagas, compondo listas de espera nas instituiçôes públicas. Nessa direção, o conhecimento dos significados, para as famílias, das políticas de Educação Infantil no que se refere ao acesso e à qualidade do que é oferecido pelas IEI públicas é relevante para informar políticas e práticas nessa área. A relevância é ainda reforçada pelo fato de que o acesso de pesquisadoras(es) às(aos) professoras(es) é mais frequente do que o acesso aos familiares. Assim, tem sido mais comumente registrado e analisado o ponto de vista da escola sobre a família do que o contrário. Observa-se que as avaliaçóes negativas 
da primeira em relação à segunda, conforme constata Monção (2015), são não apenas frequentes como, não raro, desencadeiam açôes de controle e disciplinamento que extrapolam e se somam às inerentes ao caráter institucional da Educação Infantil.

A perspectiva hegemônica na área da Educação Infantil é a da indissociabilidade entre cuidado e educação. Essa perspectiva se traduz na ideia de que, ao cuidar da criança, entra em curso também a dimensão educativa. Considera-se que não é possível interagir com crianças pequenas sem que haja aprendizagens, formação de imagens e de referências sobre o outro e o 'mundo' e, fundamentalmente, de autoimagens e de certa compreensão de si mesmo. De forma mais direta, a própria aprendizagem das práticas de cuidado e de autocuidado que ocorre nessas relações também constitui elemento da construção da ideia da indissociabilidade entre cuidado e educação (CAMPOS, I994; DUMONT-PENA; SILVA, 2018). Isso não quer dizer, no entanto, que essa forma de conceber as relações entre cuidado e educação esteja generalizada nas concepções e práticas das instituiçôes de Educação Infantil: o que se observa é que, na Educação Infantil, por vezes, ficam subsumidas as açóes de cuidado, ou, quando essas ganham visibilidade, aparecem desconectadas das concepçóes e práticas da educação das crianças, sendo realizadas, inclusive, por profissionais distintos da(o) professora(or), no caso, pelas(os) chamadas(os) auxiliares de sala. (BITTENCOURT; SILVA, 20I7)

Aspecto fundamental das políticas e práticas de Educação Infantil se refere à oferta de instituiçôes com atendimento às crianças em horário integral. Essa modalidade de jornada reflete concepçóes de Educação Infantil e, também, aporta ao campo demandas, nos planos político e pedagógico, que buscam concretizar os direitos das crianças e das famílias. $\mathrm{O}$ regime de atendimento em horário integral é uma das respostas dadas pelo Estado para favorecer a inserção da mulher no mercado de trabalho, o que aumenta o tempo de ação da escola com a criança, tornando-o semelhante ao tempo de ação da família nos dias letivos. Araújo (20I6, p. 193-4) adverte para o fato de que as demandas sociais e econômicas das famílias "não são reconhecidas como elementos indutores de políticas públicas estruturantes, o que termina por desencadear uma nova institucionalizaçáo da infância pela via da oferta do tempo integral nas creches e pré-escolas." E que, muitas vezes, são as próprias crianças 'incluídas' por meio de critérios 
de seleção que "continuam a expor demandas sociais não contempladas em seus contextos reais de vida." Trata-se de questáo complexa que ultrapassa a mera dimensão temporal com a problematização da oferta de educação integral ou tempo integral na educação.

Além disso, a frequência das crianças cada vez mais cedo a uma instituição educacional altera as práticas familiares, não apenas no que concerne a questóes objetivas quanto a cumprimentos de horários e regras institucionais, mas também no que se refere às orientaçôes de suas ações para com os filhos (SILVA, 20I4). Assim, especialmente as mães têm revelado transformação nas formas de cuidar e educar seus pequenos em face das exigências da escola. Além disso, revelam que o contato diário com professoras nas IEI proporciona a elas novas aprendizagens sobre as crianças, seu processo de desenvolvimento e suas necessidades. Esses elementos aparecem, no entanto, tanto sob a forma positiva de ampliação das referências de mães e pais a respeito dos filhos quanto sob a forma de conflitos e angústias: de um lado, certa pressão por incorporar parâmetros supostamente científicos na relação com os filhos; de outro, expressão de conflitos quando tais aprendizagens implicam questionamento de valores fortemente enraizados nas práticas familiares. Observa-se, assim, que elementos do senso comum das famílias estão se enfraquecendo, na medida em que elas revelam dificuldades em tomar decisóes cotidianas com relação às crianças pequenas, ou mesmo de exercerem a autoridade parental, questionando-se e buscando parâmetros de ação supostamente universais e 'eficazes'. (SILVA, 2012; 2014)

O fato é que a Instituição de Educação Infantil introduz elementos que não se restringem à adaptação da criança à cultura escolar (algo pouco analisado) ou a possibilidades familiares de cooperaçáo com o trabalho da escola. Quanto mais cedo a criança (bebê) vai para a escola, mais o âmago das funçóes dos adultos familiares é atingido. Inclusive porque, além das questôes acima arroladas, outros elementos se interpóem: a vida íntima da família se vê desvelada pela instituição educacional (SILVA, 20I2; 20I4). Esse desvelamento ocorre de diferentes formas: desde a informação de detalhes da vida da família para concorrer a vagas no insuficiente sistema público, passando pelas entrevistas de matrícula até o que é revelado pelas mochilas das crianças em termos de padrôes de consumo, cuidados de hi- 
giene e alimentação, até as formas e orientaçóes adotadas nas relaçóes dos adultos familiares com os bebês e crianças pequenas. (SILVA, 20I2)

Considerando que é função da Educação Infantil compartilhar cuidado e educação com as famílias, conhecer seus pontos de vista se revela como condição necessária para a construção das práticas nas IEI. Nessa direção, este artigo analisa pontos de vista de familiares sobre a frequência de seus filhos e filhas à Educação Infantil com o objetivo de adensar a própria noção de compartilhamento.

A pesquisa ${ }^{2}$ que deu origem a este artigo foi desenvolvida no período de 2013 a 20I6, em uma Escola Municipal de Educação Infantil (EMEI) localizada em um aglomerado de vilas na Região Oeste de Belo Horizonte. A pesquisa objetivou analisar as relaçóes entre as famílias e a Instituição de Educaçáo Infantil, tendo sido realizada por meio de estudo de caso (ANDRÉ, 2005 e 20I3; YIN, 20Io). Foram utilizadas, como estratégias metodológicas a observação participante com registros em diários de campo, entrevistas, análise documental e grupos focais com familiares. Neste artigo, a fonte de dados utilizada foram os registros dos grupos focais realizados com familiares, os quais permitiram o acesso não apenas a opinióes desses atores, mas também a um processo de reflexáo entre pares sobre questôes comuns a todos(as).

Os grupos focais foram planejados juntamente com as professoras e coordenadoras da EMEI e realizados nas dependências da instituição pela equipe de pesquisa em um sábado pela manhã (I3/06/2015), de modo a favorecer a participação dos familiares que trabalham durante a semana. Os critérios de seleção dos(as) participantes consideraram: a presença de familiares de crianças dos dois ciclos (de o a 2 anos e de 3 a 5 anos), de crianças com deficiência e com diferentes graus de participação no cotidiano da escola. Foram organizados dois grupos, um com 8 participantes e outro com 7 , totalizando a participação voluntária de Is familiares: pais, mães e uma avó. As sessões foram gravadas em áudio e transcritas integralmente. As análises seguiram a técnica de análise de conteúdo (BARDIN, 20II), com a categorização dos dados e identificação de recorrências e dissonâncias, de modo a apreender a complexidade das concepçóes e práticas. (MINAYO, 20I2)

Temos consciência de que o compartilhamento supóe os dois polos da relação - famílias e IEI. Mas, nos limites deste artigo, trataremos dos 
pontos de vista dos familiares uma vez que esses atores são, ainda, os menos conhecidos no processo educacional formal. Nosso objetivo foi o de conhecer e analisar os pontos de vista e as experiências que os familiares vivenciam no processo de inserção e permanência de seus bebês e crianças de o a 5 anos na Educação Infantil. Os resultados foram agrupados nos tópicos: i- função de guarda e suas relaçóes com a confiança, a segurança e o bem-estar; ii- conflitos e dimensóes espaço-temporais do compartilhamento.

\section{Lugar de guarda: confiança, segurança e bem-estar de crianças e adultos}

A função de guarda (MARANHÃO; SARTI, 2008; MONÇÃO, 20I5), reconhecida pela normatização da Educação Infantil e pela literatura da área, aparece, como era esperado, como um dos aspectos destacados pelos familiares pesquisados. No caso dessa instituição que atendia em horário integral (cerca de Io horas diárias), essa função se faz ainda mais importante para as famílias na medida em que, como discutido acima, a resposta a demandas econômicas e sociais das famílias que possuem crianças na faixa etária de o a 5 anos é, no contexto brasileiro, a oferta de jornada integral nas IEI. Observa-se, no entanto, que as funçóes de provisão e proteção (ARAÚJO, 20I6), asseguradas pelo Estado por meio da Educação Infantil, possuem para os familiares sentidos próprios que envolvem valores, expectativas e aprendizagens sobre a condição infantil e sobre o compartilhamento dos cuidados e educação com uma IEI.

A confiança e a segurança, favorecidas pela complementaridade, pela regularidade, pela institucionalidade e pela comunicação emergem de suas reflexóes como fatores de bem-estar familiar(crianças e adultos). São aspectos que se inter-relacionam e compóem um conjunto que proporciona uma visão sobre a EMEI construída na relação com essa instituição, tendo em vista as condiçôes gerais de vida dessas famílias. Uma série de depoimentos/reflexóes realizadas no grupo permitem compreender como essas famílias veem e o que esperam dessa instituiçáo.

Observa-se que os aspectos da confiança e segurança atravessam os demais e se apresentam relacionados a diferentes situaçôes da experiência 
das crianças e de seus familiares na EMEI. As situações que compóem esses elementos se referem ao bem-estar físico e psicológico, não apenas dos filhos e filhas, mas também dos adultos, incluindo os responsáveis diretos e outros familiares que eventualmente compartilhariam os cuidados e a educação das crianças.

O contorno físico da EMEI, que expressa um 'dentro' em oposição ao 'lá fora', a regularidade do funcionamento institucional que assegura o período diário de permanência da criança e a alimentação nos horários adequados são expressos como condiçôes de segurança e bem-estar para crianças e adultos familiares:

É porque aí eu posso trabalhar tranquilo, tenho o horário que eu sei que eles vão sair e que eles vão chegar. Sei que eles estão sendo alimentados no horário. Para mim, eu fico tranquilo lá fora trabalhando porque eu sei que eles estão em boas mãos. (Marcos, pai de Paulo e Yara - grifos nossos)

Em outro trabalho (SILVA, 20I4), discutimos a confiança como um aspecto central das relaçóes entre a família e a instituição de Educação Infantil. A confiança aparece como algo construído e que depende tanto da capacidade da instituição de se comunicar e acolher essa família quanto da comunicação entre as famílias usuárias. Essa comunicação entre famílias, em alguns casos, pode se fazer ainda mais forte do que a comunicação com professoras e direção, uma vez que esta é marcada pelas barreiras decorrentes da própria condição do vínculo institucional e do lugar social das professoras, gestoras e familiares cujo acesso a serviços públicos dessa natureza é uma experiência recente.

Nesta pesquisa, as formas de comunicação formal e informal da EMEI com os familiares revelou-se fator fundamental da confiança e segurança para os familiares:

Eles (as professoras) anotam na agenda... Não tudo que eles fazem, mas o banho, as trocas, se eles comeram ou não, se aconteceu alguma coisa, se eles machucaram.(Kátia, mãe de Joaquim e Leonardo) 
Tais informações registradas pelas professoras nas agendas eram tanto mais detalhadas quanto mais novas eram as crianças. Observe-se que as agendas de crianças de o a 2 anos e as de crianças de 3 a 5 possuíam formatos diferentes e as professoras eram instruídas a preenchê-las de formas também distintas.

Ao expressarem suas visões sobre a EMEI, os familiares o fazem em comparação com outras possibilidades. A 'opção' pela EMEI é justificada pelo caráter institucional que assegura canais e recursos de comunicaçáo sobre a criança. Embora se trate de crianças com idades entre 0 e 5 anos, esses familiares chegaram a mencionar que, caso não pudessem contar com a EMEI, as crianças poderiam ter experiências 'ruins' se ficassem na rua, sem supervisão. Referindo-se ao período em que precisou pagar uma pessoa da comunidade para cuidar do filho, uma das máes assim se expressou:

Então, eu chegava e ele sempre estava na rua e sempre aprendia coisa ruim, que náo tinha necessidade naquele momento da infância dele. Então assim, a gente sente muito porque, eu particularmente não tive uma $\mathrm{EMEI}^{3}$. (Denise, mãe de Felipe)

Querendo ou não, assim, a gente mora na comunidade, a gente sabe que tem muito estímulo pra criança que é negativo, e ele é um menino que aprende tudo muito fácil, falou que é negativo é que ele aprende mais fácil ainda. (Denise, mãe de Felipe)

Observa-se que os limites entre as casas e a rua nos arredores da EMEI se revelam pouco marcados. A alternativa de contar com a ajuda de filhos mais velhos (ou outros parentes) nem sempre assegura, para essas 
famílias, que as crianças estarão protegidas (DUMONT-PENA; SILVA, 2018). No que tem sido denominado como modelo de delegação no cuidado com os filhos (HIRATA; KERGOAT, 2007), muitas vezes quem assume o encargo de cuidar o faz de forma voluntária, concomitantemente com outros afazeres irrenunciáveis. A literatura mostra que filhos mais velhos, especialmente filhas, ou outros parentes, por vezes adolescentes, ou mesmo tias, tios, avós, dentre outros, são os recursos disponíveis para as famílias que não contam com opção de serviço público de Educação Infantil. Em muitos casos, há também um custo financeiro, na medida em que nem sempre haverá um adulto ou mesmo uma criança mais velha a quem delegar a função de cuidar sem remuneração. Para essa população, a instituição pública gratuita é elemento fundamental da qualidade de vida:

Então se torna muito importante porque antes eu tinha que pagar uma pessoa todo o tempo, porque antes ele ficava na EMEI só na parte da manhã, então eu tinha que pagar uma pessoa pra buscar e ficar até a tarde. Aí voltando no assunto que eles[demais participantes do Grupo Focal] falaram:[pagar] outra pessoa, aí você paga, é um dinheiro muito suado. É uma responsabilidade muito grande e a pessoa sabe que é uma responsabilidade muito grande. (Denise, mãe de Felipe)

Nesse modelo de delegação, os custos assumidos pelas mulheres são, em geral, mais altos, pois são elas que deixam o trabalho.

Karla (mãe de Marcos e Daniel): Eu pensei em sair do serviço também, ainda mais quando descobri que eram dois. Enquanto era um, minha mãe falava: Um só não precisa sair do seu serviço que eu saio do meu e eu cuido dele. Tanto que ela fez isso mesmo, mas ela acabou não dando conta. Mas [...] graças a Deus em dois meses saiu a vaga, então não precisou. Pesquisadora: Uma alternativa então é a avó? [...]. Todos [Respostas do grupo em sinal de positivo]: Sim, sim. Amilton (pai de Marcos e Daniel): Pra mim náo tinha como eu parar de trabalhar, no caso tinha que ser a mãe mesmo. 
Mesmo quando se conta com a renda de outro familiar, como o pai, a repercussão nas condiçóes de vida da família tendem a atingir diretamente as crianças, como se observa nas reflexóes desse casal que tem gêmeos na EMEI:

Pesquisadora [dirigindo-se a Karla]: Você não queria parar de trabalhar, queria manter sua vida profissional? Karla:[Sim] porque o salário dele, usávamos pra fazer [...] os gastos de casa. Então o meu salário é pra eles [os filhos].

Observa-se ainda que o cumprimento adequado da função de guarda repercute em bem-estar para a família. Os cuidados básicos realizados com as crianças se estendem para após o tempo de permanência na instituição. Uma vez que as crianças recebem todas as refeiçôes e tomam o banho na EMEI, os familiares podem se desincumbir dessas tarefas ou tê-las amenizadas após sua jornada de trabalho:

Ela chegava e náo precisava de preocupar com nada, porque eu sabia [...] que ela estava bem alimentada, que ela estava limpinha, que ela estava bem cuidada. (Renata, mãe de Gilson e Gilda)

Há uma economia de tempo e energia, o que se expressa na afirmação de que "não precisava de preocupar com nada", ou seja, após sua jornada de trabalho, as tarefas com os filhos que passaram o dia na EMEI se reduzem, o que, possivelmente, se reflete também nas despesas com alimentação e materiais de higiene para as crianças em casa, fator que não pode ser negligenciado considerando tratar-se de populaçáo pobre de um aglomerado urbano.

Podemos observar que a Educação Infantil é uma alternativa que aparece ponderada em relação a outras possíveis. No caso desse casal (Karla e Amilton), pais de gêmeos, contar com a avó e a saída de um dos pais, no caso, a mãe, do mercado de trabalho, foram alternativas cogitadas. Embora a complexificaçáo da vida nos grandes centros urbanos, com as transformaçóes no mercado de trabalho, na estrutura das famílias, dentre outras, cada vez mais nos indique a inexistência ou redução de redes de 
apoio familiares (SILVA, 20I6), vemos que em alguma medida elas ainda persistem. No caso acima, revela-se a inserção mais frágil da mulher no mercado de trabalho, bem como a manutenção da regra de que, entre o pai e a mãe, quem deixa o emprego é a mulher, que pode ser a mãe ou a avó.

Nessa direção, a complementaridade se revela também no aspecto econômico, o que é pouco discutido na área da Educação Infantil. Esse aspecto tem sido mencionado, especialmente por economistas, referindo-se aos custos com educação como investimento que repercute nos índices de desenvolvimento do país, já que a frequência à Educação Infantil tende a favorecer o desempenho nos níveis subsequentes, contribuindo para qualificação do trabalhador de um modo geral. E, no que se refere às desigualdades entre homens e mulheres, a Educação Infantil pública, como reconhecido por organismos multilaterais como a OCDE, se reafirma como importante instrumento das políticas públicas para a igualdade entre os sexos.

\section{Os conflitos e a dimensão espaço-temporal do compartilhamento}

Embora tomado como um dado, compartilhar se revela como processo a ser construído cotidianamente, na relação entre a escola de Educação Infantil e a família. Envolve a construção de referências sobre os papéis dos adultos das duas instituições, a conjugação espaço-temporal e as concepçôes de infância, criança e educação. Situaçôes discutidas nos grupos focais permitem compreender como esses elementos se afiguram para os familiares e possibilitam avançar na própria ideia de complementaridade entre famílias e escolas de Educação Infantil. Como vimos no tópico anterior, os familiares que participaram da pesquisa destacaram a comunicação como um importante elemento para o estabelecimento da confiança na instituição e, consequentemente, no bem-estar dos responsáveis.

Durante os grupos focais, ao mesmo tempo em que os familiares valorizavam a prática da escola de manter os pais informados sobre o que ocorre com a criança por meio da agenda da escola (que é uma prática em toda a rede municipal), demandavam que também para as crianças de 3 a 
5 anos houvesse relatos mais detalhados como mudanças na alimentação, no sono ou em outras situaçóes relacionadas à saúde:

[Ficamos] até tristes porque quando está aqui embaixo [bloco das crianças de o a 2 anos], vai tudo bonitinho: comeu tudo, comeu isso... Ai cresce e só vai falando na agenda: medicação dada conforme receita. Aí teve até um dia que vi a professora falei: gente, sinto falta daquele "comeu tudo, dormiu, não dormiu". Cadê? [A professora responde]: "Mãe, eles cresceram, né? É um rapaz, é uma moça." (Renata, mãe de Gilson e Gilda)

Observa-se no excerto acima a percepção de que há uma suposta atribuição, por parte da EMEI, de capacidade das crianças de 3 a 5 anos informarem aos familiares sobre suas vivências. Ou mesmo o entendimento de que, nessa faixa etária, tais informaçóes não são mais necessárias, visão que não é compartilhada pelos familiares participantes. Para esses familiares, a importância de manutenção da regularidade das informaçóes para as crianças mesmo após os 3 anos se justifica como condiçáa para darem continuidade ao cuidado e à educação em casa, como em relação à alimentação. A informação sobre como a criança se alimentou na EMEI permite aos familiares tomarem decisão sobre se é ou não necessário oferecer e se empenhar para que a criança se alimente em casa após a escola, por exemplo.

Observa-se a demanda por informaçôes sobre as ações que mais se aproximam do que ocorre também no ambiente familiar, ou seja, das práticas que de fato se repetem nos dois ambientes em que a criança vive. Trata-se de um elemento relacionado ao bem-estar da criança que afeta também o bem-estar dos familiares, gerando dúvidas se, no conjunto das experiências das crianças (casa e EMEI), elas estão recebendo os cuidados na quantidade e qualidade necessárias. $\mathrm{O}$ caráter de complementaridade ficaria, nessa perspectiva, comprometido. Possivelmente, o que orienta a EMEI e as professoras é o reconhecimento das conquistas das crianças, que vão progressivamente reduzindo a dependência, especialmente pelo maior desenvolvimento da capacidade de comunicação verbal. No entanto, no que se refere aos cuidados pessoais, a visão dos familiares parece ser 
diferente, na medida em que devem ser assegurados pelos adultos por um período mais longo na infância visando a manutenção da saúde.

Diferentemente do caso acima que se referia às condiçóes de continuidade das açôes de cuidado entre escola e casa, uma situação de conflito discutida no grupo permite compreender melhor o compartilhamento de responsabilidades. A discussão girou em torno das situaçôes em que os responsáveis são chamados à escola para buscar a criança quando se verificam situaçóes de adoecimento que contraindiquem a sua permanência no ambiente escolar. Nesses casos, a ação da escola é avaliada como bem-vinda e, mesmo que cause algum transtorno para o responsável que precisa deixar o trabalho mais cedo, é entendida como uma necessidade da criança que só pode ser atendida pelo familiar. Há situaçóes, no entanto, que geram conflitos e que foram discutidas pelos familiares durante a realização dos grupos focais. Uma mãe comentou sobre o fato de ter sido chamada para comparecer à escola porque seu filho havia machucado uma colega. A máe relata sua insatisfação por ter sido obrigada a deixar o trabalho durante o expediente, destacando que considerou inadequada a açáo pelo fato de que, se o incidente ocorreu na escola, o filho estava sob a responsabilidade das professoras. Assim, não considerava adequado ser 'cobrada' pelo seu comportamento, o que, na sua visão, deveria ser dirigido às professoras. Os machucados e o adoecimento das crianças são fontes de preocupação das IEI e professoras e este parece ser um dos aspectos que pode ter motivado a postura de exigir da mãe o comparecimento imediato à instituição. Essa mãe questionou sobre como poderia ser responsável pelo comportamento do filho em um momento em que ele estava na EMEI e sobre a real necessidade de que ela se ausentasse do trabalho para comparecer à instituição.

Denise (mãe de Felipe): Aí teve um dia que aconteceu deles terem brigado, o Felipe tirou bastante sangue do nariz da Luana. Aí eu tive que sair correndo do meu serviço [...]Eu realmente xinguei. Aí eu pedi pra chamar o Felipe. E perguntei [...] para o Felipe. Ele, de primeira, falou que teve três episódios da briga até chegar aos outros. Aí, assim, eu particularmente achei falta de atenção da professora, sim. Miriam (mãe de Maíra e Luana): Comunicação, né? Denise (mãe de Felipe): Entendeu? Porque se seguidamente teve briga, ela mordeu o dedo dele, como é 
que é? Miriam (mãe de Maíra e Luana): ela mordeu ele e bateu nele dois dias. [...] Denise (mãe de Felipe): aí na hora que tirou sangue me chamam. O Felipe estava no cantinho da disciplina. Aí na hora a Luana veio. E o Felipe foi e deu um soco nela. Entáo, eu falei: "Felipe, o que sua professora estava fazendo na hora que ela não viu, ela te colocou no canto da disciplina e não viu você brigando com a Luana"? [...]Aí eu xinguei, o que eu vou falar para a mãe da criança? Mesmo porque eu náo tenho que falar nada. Porque a partir do momento que eu coloco ele aqui, é de responsabilidade [da escola]. Porque se você acha que ela (mãe da menina machucada) vai cobrar de mim, ela não vai cobrar de mim. Ela pode cobrar de mim num impulso, chamar a atenção do meu filho. [...] Ela vai cobrar da escola[...] A gente gosta de participar, se ligar a gente vem e busca, está passando mal a gente busca[...] Mas a partir do momento que está dentro da escola, é responsabilidade da escola.

Para as questóes pelas quais somente o familiar pode se responsabilizar, como no caso de adoecimento que impeça a permanência da criança na escola, essas mães revelam o reconhecimento de que devem se mobilizar 
Em outra situação, referindo-se às preferências alimentares das crianças, os participantes do grupo focal ofereceram elementos para a compreensão da dinâmica das decisôes adultas em relação às crianças nos ambientes familiar e institucional.

Priscila (mãe de Melissa): eu sei que é a idade, eu sei essas coisas, mas a minha menina, ela não gosta de vitamina. Aí um dia eu cheguei no [horário do] café [...] na hora que eu estava saindo eu vi a professora xingando ela. Ela náo gosta. Eu falei: "o que aconteceu?" Ela não gosta de vitamina, então ela não é obrigada. Não é obrigada a tacar as coisas na boca [...] aí eu fiquei brava, eu briguei. Ela não gosta de vitamina. "Quando tiver vitamina, você não precisa de dar a ela, mal mal um toddy". Não gosta, não gosta. Miriam (mãe de Maíra e Luana): a Luana em casa ela não come nada. Milton (pai de Maíra e Luana): Nada de legumes. Miriam (mãe de Maíra e Luana): aqui ela come tudo.

Ao falar da demanda de que a filha não seja obrigada a comer o que não gosta, uma das mães acena para a singularidade da criança; já o pai e a mãe de outras crianças chamaram a atenção para o fato de que, na EMEI, a filha come alimentos que não come em casa, o que foi avaliado positivamente. A possibilidade do contraponto veio no próprio momento em que a mãe da primeira criança questionou a obrigatoriedade da ingestáo do alimento rejeitado pela filha. Observa-se que no mesmo trecho os familiares comentam sobre a imposição de alimentos e da diferença na sua ingestão no ambiente da EMEI e no ambiente familiar. No que se refere à alimentação, prática cotidiana nos dois ambientes, há posiçôes divergentes tanto entre os pais quanto entre estes e a EMEI.

O que está em questão é como conciliar o caráter coletivo das açôes no ambiente institucional com as singularidades das crianças. Essa tensão revela, sobretudo, a questão da compreensão dos vínculos entre cuidado e educação, estando presentes elementos da aprendizagem dos adultos e das crianças. Com relação aos primeiros, trata-se da aprendizagem de que a alimentação não é apenas um intervalo entre as atividades pedagógicas, mas uma ação carregada de significados culturais e afetivos (MARANHÃO, 
20II). No caso das crianças, trata-se da experiência de serem cuidadas e educadas para uma alimentaçáo adequada, o que depende do sentido que os adultos atribuem a essa prática social. E, na relação entre as famílias e a EMEI - que necessariamente envolve também as crianças - revelam-se dissonâncias que parecem decorrer justamente da ausência de compartilhamento, não das ações, mas dos sentidos das açôes.

Nas situaçóes acima referidas entendemos que a máe questionou o modo como o alimento estava sendo oferecido para a filha. Tanto esse relato quanto o que se refere à questão da presença da mãe na escola diante de situaçóes de conflitos entre as crianças revelam que, na relação entre familiares e profissionais da EMEI, a criança estava presente na situação em que o dissenso se evidenciou. Embora as manifestaçóes das mães nos momentos mesmos dos acontecimentos possa indicar haver certo grau de liberdade na relação com a EMEI, observa-se que a insuficiência da compreensão mútua do que consiste compartilhar cuidado e educação submete as crianças a situaçóes desconfortáveis no processo educativo.

\section{Consideraçóes Finais}


no, com uma população pobre e, em alguns casos, em situação de grande vulnerabilidade. Essa instituição se esforçava e obtinha êxito em ofertar um atendimento que perseguia a qualidade da educação das crianças, o que incluía as relaçóes com os familiares. No entanto, o desvelamento das minúcias que constituem essas práticas nos auxiliam a avançar na compreensão de possibilidades que contribuam para concretizar a ideia de compartilhamento.

As análises dos dados construídos com os familiares das crianças, em situação coletiva, de reflexão sobre a IEI e suas repercussóes na vida das crianças e da família indicam elementos constitutivos da ideia de compartilhamento, sem, no nosso entender, tê-la esgotado. Como elementos de fortalecimento foram evidenciados a construção da confiança mútua, o estabelecimento de uma comunicaçáo efetiva e a promoçáo de bem-estar que inclui não apenas as crianças, mas também os adultos familiares. Este é, a nosso ver, um aspecto que se revelou como mais um elemento da compreensão da ideia de compartilhamento, de modo a incluirmos a dimensão afetiva e a das práticas familiares com as crianças no ambiente doméstico.

As análises indicam também outros elementos no campo dos sentidos que precisam ser ajustados entre familiares e profissionais, uma vez que geram conflitos e dificuldades na construção de práticas compartilhadas. E, para finalizar, não se pode deixar de mencionar o papel das crianças na comunicação de suas experiências, a consideração de suas singularidades, seja nas práticas alimentares, seja nas relaçóes entre pares na instituição. Evidenciou-se a necessidade de escuta mais atenta desses sujeitos para que seja possível construir práticas mais alinhadas entre a instituição e as famílias e que tragam benefícios para as experiências das crianças nos dois contextos.

Ressalta-se, portanto, a complexidade desse contexto em que as práticas internas à IEI ultrapassam seus muros no transcurso mesmo da jornada diária das crianças e professoras e se estendem para os tempos, os espaços e as relaçóes no âmbito familiar.

Ao que nos parece, os desafios que se apresentam se enquadram em uma perspectiva abrangente dos processos vivenciados na Educação Infantil: a possibilidade da construção de um ambiente confortável para crianças, familiares e professores. (MALAGUZZI,1999). 


\section{Notas}

I Agradecimentos a Fundação de Amparo à Pesquisa do Estado de Minas Gerais (FAPEMIG), à Coordenação de Aperfeiçoamento de Pessoal de Ensino Superior (CAPES) e ao Conselho Nacional de Desenvolvimento Científico e Tecnológico (CNPq) pelo financiamento da pesquisa que originou este artigo.

2 A pesquisa foi submetida e aprovada pelo Comitê de Ética em Pesquisa da Universidade Federal de Minas Gerais e todos os nomes utilizados sấo fictícios.

3 Substituímos o a sigla UMEI por EMEI que é a denominação das instituiçóes de Educação Infantil do município de Belo Horizonte a partir de 2018.

\section{Referências}

ANDRÉ, M. E. D. A. O que é um estudo de caso qualitativo em educação? Revista da FAEEBA - Educaçáo e Contemporaneidade, Salvador, v. 22, n. 40, jul./dez. 2013, p. 95-I03.

ANDRÉ, M. E. D. A. Estudo de caso em pesquisa e avaliação educacional. Brasília: Liberlivro, 2005 .

ARAÚJO, V. C. Educação infantil em tempo integral ou educação em tempo integral na educação infantil: um debate necessário. In: REIS, M.; BORGES, R. R. (Org.). Educação Infantil: arte, cultura e sociedade. Ied.Curitiba: CVR, 20I6. p. I89-208.

BARDIN, L. Análise de conteúdo. Lisboa: Ediçóes 70, 20 I.

BRASIL. Constituição (1988). Constituição da República Federativa do Brasil. Brasília, 5 out. I988.

BRASIL. Lei federal no 9.394. Estabelece as diretrizes e bases da educação nacional. Brasília, 23 dez. 1996.

BRASIL. Conselho Nacional de Educação. Câmara de Educação Básica. Resolução CEB no 5 de 17 de dezembro de 2009. Diretrizes Curriculares Nacionais para a Educação Infantil. Brasília, 2009.

BITTENCOURT, L. C. A.; SILVA, I. O. O cuidado e educação das (os) bebês em contexto coletivo: a construção da experiência da auxiliar de apoio à educaçáo infantil na interação com bebês e professoras. Zero-a-Seis, Florianópolis, v. 19, n. 36, dez. 2017, p. 379-396.

CAMPOS, M. M. M. Educar e cuidar: questóes sobre o perfil do profissional de educação infantil. In: MEC/SEF/DPEF/COEDI. (Org.). Por uma politica de formação do profissional de educaçâo infantil. Brasília: MEC/SEF/DPEF/COEDI, 1994, p. 32-42. 
DUMONT-PENA, E.; SILVA, I. O. Aprender cuidar: diálogos entre saúde e Educação Infantil. São Paulo: Cortez, 2018.

HADDAD, L. A creche em busca de identidade. São Paulo: Loyola, I99I.

HIRATA, H.; KERGOAT, D. Novas configurações da divisão sexual do trabalho. Cadernos de Pesquisa, São Paulo, v. 37, n. I32, set./dez. 2007, p. 595-609.

KUHLMANN Jr., M. Infância e Educação Infantil: uma abordagem histórica. Porto Alegre: Editora Mediação, 1998.

MARANHÃO, D. G; SARTI, C. A. Creche e família: uma parceria necessária. Cadernos de Pesquisa, São Paulo, v. 38, n. I33, jan./abr. 2008, p. I7I-I94.

MARANHÃO, D. G. O cuidado de si e do outro. Educação, São Paulo, v. 2, 20 I, p. I4-29.

MARANHÃO, D. G.; SARTI, C. A. Cuidado compartilhado: negociaçôes entre famílias e profissionais em uma creche. Interface - Comunicação, Saúde, Educação, Botucatu, v. II, n. 22, mai./ago., 2007, p. 257-270.

MALAGUZZI, L. História, ideias e filosofia básica. In: EDWARDS, C.; GANDINI, L.; FORMAN, G. (Org.). As cem linguagens da criança: a abordagem de Reggio Emilia na educação da primeira infância. Porto Alegre: Artmed, I999. p. 59-I04.

MINAYO, M. C. S. Análise qualitativa: teoria passos e fidedignidade. Revista Ciência e Saúde Coletiva para a Sociedade, Rio de Janeiro, v. I7, n. 3, mar. 2012, p. 621-626.

MONÇÃO, M. A. G. O compartilhamento da educação das crianças pequenas nas instituições de educação infantil. Cadernos de Pesquisa, São Paulo, v. 45, n. I57, set. 2015 , p. 652-679.

NOGUEIRA, M. A. Família e escola na contemporaneidade: os meandros de uma relação. Educação e Realidade, Porto Alegre, vol. 31, n. 2, jul./dez. 2006, p. I55-I69.

RAPOPORT, A.; PICCININI, C.A. A escolha do cuidado alternativo para o bebê e a criança pequena. Estudos de Psicologia, Natal, vol. 9, n. 3, dez. 2004, p. 497-503.

ROSEMBERG, F. Avaliação de programas, indicadores e projetos em Educação Infantil. Revista Brasileira de Educação, Rio de Janeiro, n. I6, jan./abr. 200I, p. I9-26.

ROSEMBERG, F. O movimento de mulheres e a abertura política no Brasil: o caso da creche. In: ROSEMBERG, F. (Org.). Creche (Temas em destaque). São Paulo: Cortez/ Fundação Carlos Chagas, I989. p. 90-103.

SILVA, I. O. Educação Infantil no coração da cidade. São Paulo: Cortez, 2008. 
SILVA, I. O. Crianças de o a 2 anos em instituição de Educação Infantil: entre educadoras e mães. In: REIS, M.; XAVIER, M. C; SANTOS, L. (Org.). Crianças e Infâncias: educação, conhecimento, cultura e sociedade. I ed. São Paulo: Annablume, 20I2, p. 33-49.

SILVA, I. O. A creche e as famílias: o estabelecimento da confiança das mães na instituição de educaçáo infantil. Educar em Revista, Curitiba, n. 53, set. 2014, p. 253-272.

SILVA, I. O. A educação infantil no Brasil. Pensar a Educação em Revista, Curitiba/Belo Horizonte, v. 2, n. I, jan-mar/2016, p. 3-33.

VIEIRA, L. M. F. Creches no Brasil: de mal necessário a lugar de compensar carências rumo à construção de um projeto educativo. I986. Dissertação (Mestrado). Faculdade de Educação, Universidade Federal de Minas Gerais, Belo Horizonte, 1986.

VIEIRA, L. M. F. Mal necessário: creches no Departamento Nacional da Criança (1940-1970). Cadernos de Pesquisa, São Paulo, n. 67, nov. 1988, p. 3-16.

YIN, R. K. Estudo de caso: planejamento e métodos. Porto Alegre: Bookman, 20 Io.

Recebido em 6 jun. 2019 / Aprovado em 4 set. 2019 Para referenciar este texto:

SILVA, I. O.; LUZ, I. R. Relaçōes entre famílias e instituições de educação infantil: o compartilhamento do cuidado e educação das crianças. EccoS - Revista Científica, São Paulo, n. 50, eI4IIo, jul./set. 2019. Disponível em: https://doi.org/10.5585/EccoS. n50.14III. 